\title{
A Comparative in Vivo Study on Bambusa Polymorpha, Mentha Piperita and Clitoria Ternatea as Alternative Anxiolytic
}

\author{
T. S. Tunna, M. S. Akter, M. Parvin, M. Jilhaz, S. Jahan, and I. S. M. Zaidul
}

\begin{abstract}
This is a continuation of our "Stress Management with Herbal Alternatives" project whereby we are testing traditionally used herbs to scientifically establish their efficacy as anxiolytics for the $1^{\text {st }}$ time. For the current study Bamboo leaf tea, Mint leaf tea and Clitoral bush petal tea were compared for their anxiolytic potency. Male Swiss albino mice were used to test on Open Field test (OFT) and Elevated Plus Maze (EPM) anxiety model. Diazepam (at the dose of $0.25 \mathrm{mg} / \mathrm{kg}$ body weight) was used as standard and Bangladeshi indigenous bamboo aka Bambusa polymorpha or Bamboo, Mentha piperita or Mint and Clitoria ternatea or Clitoral Bush (at doses of $1 \mathrm{~g} / \mathrm{kg}$ body weight) were the sample. The control group had no intervention. For OFT we tested line crossing, time spent in center, time spent in thigmotaxis and for EPM we measured the number of entry in open and closed hands, time spent in the open and closed hands. Parameters such as rearing, grooming, urination and defecation were also monitored for both tests.The trial results showed Clitoral bush and Mint leaves to have greater anxiolytic activity than Bamboo and Diazepam. Bamboo and Clitoral Bush helped in weight loss, wherelse Diazepam caused weight gain. Based on all criteria, Clitoral bush tea showed highest potential to reduce stress as well as stress related obesity. Results were followed by mint, diazepam and bamboo respectively in their potency for anxiolytic effect.
\end{abstract}

Index Terms-Stress Management, Bamboo Leaf Tea, Clitoral Bush Petal Tea, Mint Tea, Holistic Health, Anxiolytics, Open Field Test, Elevated Plus Maize.

\section{INTRODUCTION}

Stress and anxiety is now the bane of existence of humankind. It has seeped into our lives to the extent that we can't think of life without having to perpetually being stressed about one thing or another. Stress has direct correlation to myriads of diseases which were previously thought to be only caused by either genetics or food habits. Stress is the culprit behinds diseases such as diabetes, cardiovascular disorders, respiratory issues, memory loss, immune disorders, allergy, asthma, acne, gastric disorders and other myriad of issues [1-4]. Since it will always be a part of human life, it is better to learn to cope and reduce the effects with daily habits or rituals to calm oneself. It is essential to be able to zone out and relax once in a while if not daily.

Stress management can be easily incorporated into our daily lives with as simple as doing regular yoga, breathing exercises as well as other forms of exercises which releases stress and tension by producing endorphins that are known

Published on May 22, 2020 as the feel-good hormones [5]. Along with those stress management can be accomplished by the use of various traditional herbal systems such as the Chinese, Japanese, Ayurvedic systems [6,7]. Herbal tea drinking is a ritual taking the world over. It's a calming and grounding habit that has been seen to provide immense benefit to our physical and mental health

Our quest is to bring the attention towards natural and healthier way of stress and anxiety management which as we can see is the root of all disease. If we can manage stress, then it will be the best mode of prevention of disease in the first place. We testes three natural anxiolytics which are revered in many cultures but don't have proper scientific backup. Our first specimen is Bamboo which is an integral part of Chinese and Japanese culture as bamboo symbolizes the strength, virility and vitality of the culture and emulates many strengthening properties [8]. Bamboo leaf is a great source of silica which is great for skin and hair, bamboo leaf tea is purported to have calming effect along with providing non-caffeine source of antioxidants as opposed to green tea [9]. Bamboo is rich in antioxidant, triterpenoids etc and has properties such as antidiabetic, anti-inflammatory, antiulcer etc. [9] (Rathod et al., 2011). Study also found the presence of vitexin, isovitexin, rutine, orientin and isoorientin in bamboo which are strong flavonoids that fight inflammation and lipid oxidation while protecting the heart and brain functions [10] (Sun et al., 2010). Common bamboo species indigenous to, but not limited to, Bangladesh are Bambusa arundinaceae, $B$. vulgaris and B. polymhorpha. There have been some studies involving the $B$. vulgaris and $B$. arundinaceae but very little if any was found on $B$. polymorpha the world over. The current study took the age old Traditional Chinese ritual of drinking bamboo leaf tea and tested for its efficacy. To the best of our knowledge, the study of anxiolytic or calming effect of bamboo leaf tea is the first scientific reporting.

The second specimens we tested was Mentha piperita or Mint leaves although traditionally cultivated in the Middle eastern and Mediterranean regions is now grown worldwide and venerated for its amazing ability as anxiolytic, as skin active, to reduce gas and bloating and also in various culinary purposes [11]. Mint has been used for digestive issues such as, gas, bloating, indigestion, diarrhea, cramping and anorexia [12]. It supports neurological functions and has renal activities too [12]. Mint is traditionally drunk in the Middle Eastern countries and it is now gaining popularity as holistic calming herb not just for gastric troubles but also as anxiolytic. The third agent that we are testing in this study is Clitoria ternatea also known as Clitoral bush (CB) or 
butterfly pea. It is grown mostly for its aesthetic purposes but some eastern countries such as Indonesia and Malaysia are utilizing this for culinary purpose as natural food colourant. It is used in Ayurveda as a memory boosting and nerve calming agent [13]. This study is an attempt to establish the anxiolytic potency based on EPM and OFT based models for assessing the stress adapting properties of the chosen herbal specimen. It is the second part of our ongoing "Stress Management with Herbal Alternatives" project whereby we tested the efficacy of various herbal infusions and implements that are integral part of various cultures across the world but were not scientifically authenticated. The first sample we tested was Rose petal tea as anxiolytic which is an integral part of the Middle Eastern culture [14]. The aim of this journey was to explore the realm of alternative medicine for management of stress which is an integral part of our modern lives. The experimental herbs chosen have very outdated study results and there have not been much research on their anxiolytic properties for the past decade and hence were chosen to make a comeback. Anxiolytics have purported various side effects including stomach issues, diarrhea, confusion, tolerance and dependency [15]. Anxiolytic overuse and addiction is now a global issue. Our aim was to introduce natural therapeutic implicates from the various culture around the world, test the ones that were never scientifically tested before to establish their efficacy and create awareness on their benefits as opposed to anxiolytics to manage stress and stress related issues.

\section{MAterials AND Methods}

\section{A. Sample preparation}

Leaves of intermediately aged bamboo trees or Bambusa polymorpha, peppermint or Mentha piperita and clitoral bush or Clitoria tertea were collected by the authors during the blooming season from February through May, 2018. The leaves were washed and dried under shade at a temperature controlled room $\left(25^{\circ} \mathrm{C}\right)$. After drying, the dried leaves were shredded and then stored in air tight jars in a temperature controlled room until future use. $550 \mathrm{~g}$ of dried tea was harvested. For the dosage, $1 \mathrm{gm}$ of the loose tea would be steeped in purified water for 20 mins with the temperature kept at $60-70^{\circ} \mathrm{C}$ so as to preserve as much of the bioactive as possible allowing much extraction to have taken place. The specimens were preserved and submitted to the herbarium of the Department of Pharmacy, Primeasia University (PAU) Bangladesh. The botanical authentication was done by the in-house Botanist of the Department of Pharmacy, PAU.

\section{B. Animal}

Male Swiss Albino mice (27-31 gm) were procured from Jahangirnagar University, Bangladesh for the experimental procedure. They were housed at a separate facily in temperature and light controlled condition. 6 mice were put in each cage for each group of Control (no change marked C1-6), Standard (Diazepam $0.25 \mathrm{mg} / \mathrm{kg}$ body mass marked $\mathrm{S} 1-6)$, Bamboo leaf tea (1 $\mathrm{g} / \mathrm{kg}$ body weight marked as BP 16), Mint leaf $(1 \mathrm{~g} / \mathrm{kg}$ body mass marked as MP 1-6) and Butterfly pea or Clitoral bush leaf tea $(1 \mathrm{~g} / \mathrm{kg}$ body mass marked as CB 1-6). The mice were fed AdLibitum and kept in very hygienic and calm condition. Extraneous stressors were removed as much possible so to reduce their exposure to stressful environment hence ensuring an acceptable experimental model. The tests were chosen very carefully to avoid any means of cruelty and mishandling. Force-feeding of sample tea was done in a soothing manner. Overall it was taken into grave consideration to avoid stressing and not testing them in any harmful, painful or cruel manner. All standard ethical norms were maintained during the entire duration of the study. The study was conducted after gaining ethical board permission from Biomedical Research Center, Dhaka University, Bangladesh with the reference number BMRC/EC/2017-2018/237. The total duration for trial was 4 weeks with each test undertaken for 7 days with a 1 week habituation at the beginning and another at the end to see residual effects if any. Followed by the end of trial the animals were not discarded but was given to the Depart of Pharmacy for further studies and teaching purposes.

\section{Open Field Test maze and Elevated Plus Maze}

Both the apparatus and procedure has been explicitly described in our previous paper [14]. We have followed the same apparatuses of Open Field Test and Elevated Plus Maze along with the same parameters of stress and anxiety were measured following the same methods.

\section{RESUlt AND Discussion}

The realm of alternative medicine is having a major comeback in recent years. People are converging towards the time tested arena of Complementary and alternative medicine for holistic healing and enriched lifestyle [7]. The present study embarked on the journey to scientifically establish the efficacy of Bamboo leaf tea, mint leaves and clitoral bush or butterfly pea in transcending calmness in the experimental subjects. Both the Elevated Plus Maze (EPM) and Open Field Test (OFT) has been utilized to include as many variables into the analysis and improving the soundness of the experimental design. Our previous published paper depicted in details the parameters tested for both the tests. In short for OFT the parameters of Time spent in Center (depicted as High risk zone to rodents), Thigmotaxis (hugging the wall to avoid the open, the number of lines crossed (used for calculating Ambulation), urination, defecation and grooming were measured along with two calculated parameters of Center duration versus Thigmotaxic duration as \%CT and center duration versus total lines crossed as $\% \mathrm{CL}$. The $\% \mathrm{CT}$ and $\% \mathrm{CL}$ are two very important analytical parameters which helped us to ascertain the activity, exploration and anxiety. Urination, defecation, rearing and grooming were determined as supporting parameters as in some experiments they were seen to show higher effects than others.

For the other analysis of Elevated Plus Maze (EPM), the parameters of number of Entry in the Open area (High risk zone) versus Total number of Entries were depicted as OE/TE, the parameter of Time in Open versus Total Time as $\mathrm{OT} / \mathrm{TT}$ along with other parameters of urination, defecation, rearing and grooming were also calculated. Each trial lasted for 7 days per test, per group in alternative days to reduce experimental bias of getting used to. Below Table I-IV are depiction of the 7-day trial summary of both the EPM and 
OFT test employing the various parameters tested in the course of this research.

TABLE I: COMPARATIVE DEPICTION OF THE \%CT OF OFT TESTING FOR BAMBOO, MINT, CLITORAL BUSH, STANDARD DRUG DOSE AND CONTROL GROUP

\begin{tabular}{lccccr}
\hline \hline Days & $\begin{array}{l}\text { \%CT } \\
\text { Bamboo* }\end{array}$ & $\begin{array}{c}\text { \%CT } \\
\text { Mint }\end{array}$ & $\begin{array}{c}\text { \%CT } \\
\text { Clitoral } \\
\text { bush }\end{array}$ & $\begin{array}{c}\text { \%CT } \\
\text { Std * }\end{array}$ & $\begin{array}{c}\text { \%CT } \\
\text { Control }\end{array}$ \\
\hline Day 1 & 2.39 & 2.85 & 3.02 & 2.71 & 1.85 \\
\hline Day 2 & 1.98 & 1.98 & 3.88 & 2.33 & 0.97 \\
\hline Day 3 & 0.84 & 4.40 & 1.97 & 1.02 & 0.30 \\
\hline Day 4 & 1.05 & 2.56 & 1.44 & 1.29 & 0.65 \\
\hline Day 5 & 1.21 & 1.95 & 1.75 & 1.49 & 1.12 \\
\hline Day 6 & 1.10 & 3.55 & 2.86 & 2.44 & 1.95 \\
\hline Day 7 & 2.33 & 4.77 & 4.69 & 3.80 & 2.83 \\
\hline \hline
\end{tabular}

* \%CT comparison was found to be significant $p<0.05$

TABLE II: COMPARATIVE DEPICTION OF \%CL OF OFT TESTING FOR BAMBOO, MINT, CLITORAL BUSH, STANDARD DRUG DOSE AND CONTROL

\begin{tabular}{lccccc}
\hline \hline Days & $\begin{array}{l}\text { \%CL } \\
\text { Bamboo** }\end{array}$ & $\begin{array}{c}\text { \%CL } \\
\text { Mint }\end{array}$ & $\begin{array}{c}\text { \%CL } \\
\text { Clitoral** } \\
\text { bush }\end{array}$ & $\begin{array}{c}\text { \%CL } \\
\text { Std ** }\end{array}$ & $\begin{array}{c}\text { \%CL } \\
\text { Control }\end{array}$ \\
\hline Day 1 & 6.25 & 9.40 & 20.46 & 8.30 & 7.32 \\
\hline Day 2 & 4.91 & 8.03 & 34.56 & 5.80 & 5.45 \\
\hline Day 3 & 4.05 & 10.45 & 20.86 & 5.02 & 4.03 \\
\hline Day 4 & 3.63 & 6.62 & 13.71 & 3.68 & 2.22 \\
\hline Day 5 & 2.92 & 4.92 & 2.76 & 3.09 & 1.42 \\
\hline Day 6 & 3.41 & 6.63 & 17.05 & 4.33 & 2.27 \\
\hline Day 7 & 2.67 & 8.84 & 17.69 & 6.03 & 3.58 \\
\hline \hline
\end{tabular}

$* * \% \mathrm{CL}$ was found to be very significant $p<0.001$.

TABLE III: COMPARATIVE DEPICTION OF THE OE/TE OF EPM TESTING FOR BAMBOO, MINT, CLITORAL BUSH, STANDARD DRUG AND CONTROL GROUP

\begin{tabular}{lccccc}
\hline \hline Days & $\begin{array}{c}\text { \%OE/TE* } \\
\text { Bamboo }\end{array}$ & $\begin{array}{l}\text { TEOE/ } \\
\text { Mint }\end{array}$ & $\begin{array}{c}\text { \%OE/TE* } \\
\text { Clitoral } \\
\text { bush }\end{array}$ & $\begin{array}{c}\text { \%OE/TE } \\
\text { Std }\end{array}$ & $\begin{array}{c}\text { \%OE/TE } \\
\text { Control }\end{array}$ \\
\hline Day 1 & 24.14 & 32.63 & 28.58 & 26.25 & 20.14 \\
\hline Day 2 & 20.57 & 49.26 & 39.58 & 37.42 & 22.88 \\
\hline Day 3 & 32.12 & 58.57 & 48.84 & 47.64 & 40.83 \\
\hline Day 4 & 40.87 & 67.50 & 56.36 & 55.00 & 50.58 \\
\hline Day 5 & 42.42 & 58.94 & 57.46 & 55.89 & 42.78 \\
\hline Day 6 & 28.00 & 48.33 & 47.83 & 41.56 & 27.08 \\
\hline Day 7 & 10.00 & 33.33 & 29.50 & 27.00 & 17.04 \\
\hline \hline
\end{tabular}

* OE/TE has been found to be significant

TABLE IV: COMPARATIVE DEPICTION OF THE OT/TT OF EPM TESTING FOR BAMBOO LOW DOSE, STANDARD DRUG LOW DOSE AND CONTROL GROUP

\begin{tabular}{lccccc}
\multicolumn{2}{c}{ BAMBT/TT } & $\begin{array}{l}\text { \%OT/TT } \\
\text { Bamboo }\end{array}$ & $\begin{array}{c}\text { \%OT/TT* } \\
\text { Clitoral } \\
\text { bush }\end{array}$ & $\begin{array}{c}\text { \%OT/TT } \\
\text { Std }\end{array}$ & $\begin{array}{c}\text { \%OT/TT } \\
\text { Control }\end{array}$ \\
\hline Day 1 & 4.66 & 5.13 & 5.33 & 4.89 & 2.82 \\
\hline Day 2 & 2.52 & 5.73 & 5.93 & 4.57 & 2.93 \\
\hline Day 3 & 6.10 & 8.60 & 8.29 & 7.80 & 3.95 \\
\hline Day 4 & 6.76 & 9.20 & 9.40 & 8.21 & 5.49 \\
\hline Day 5 & 6.80 & 8.87 & 8.33 & 7.43 & 4.01 \\
\hline Day 6 & 5.24 & 6.84 & 6.58 & 5.56 & 1.88 \\
\hline Day 7 & 4.67 & 6.53 & 5.58 & 5.28 & 0.77 \\
\hline \hline
\end{tabular}

*OT/TT was found to be significant $(p<0.05)$

The comparative depiction of the \%CT (percentage presence in center cumulating to having lower stress level), $\% \mathrm{CL}$ (comparative percentage of center vs. line crossing cumulating to having lower stress level) of Open Field Test (OFT) has been depicted in Table I and II. The parameters of OE/TE (entry to open area vs. total number of entry cumulating to having lower stress level), OT/TT (time spent in open area vs. total time spent cumulating to having lower stress level) of the Elevated Plus Maze (EPM) for Bamboo leaf tea, mint leaf tea, clitoral bush tea, standard drug and Control groups are depicted in Tables III and IV respectively. The parameters of urination and defecation was found to be very negligent amount in both OFT and EPM tests and was therefore concluded to not having any effect on the testing parameters of either doses or drugs used. Also rearing has been found to of negligent importance. Both these findings are similar to our testing of rose and we can safely assume that urination, defecation and rearing have been of negligent importance for anxious or stress testing parameter.

Below Fig. 1 to 4 are depictions of comparison of bamboo, mint and clitoral bush to standard drug for both OFT and EPM. The first figure is a comparison of the \%CT and $\% \mathrm{CL}$ of Open Field Test as given below.

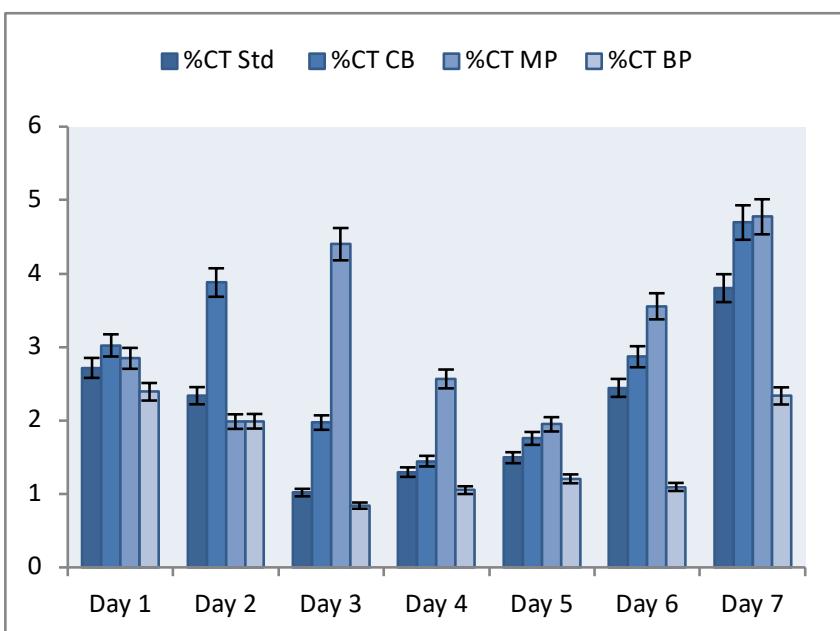

Fig. 1. Results for $\% \mathrm{CT}$ of OFT comparison of the Standard drug with Clitoral Bush (CB), followed by Mint (MP) and Bamboo (BP); \%CT comparison was found to be significant $p<0.05$

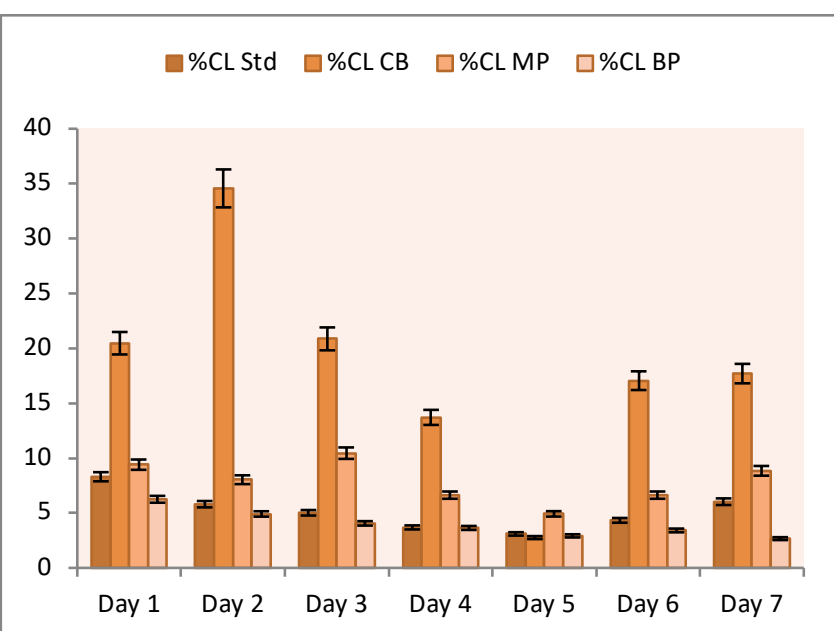

Fig. 2. Results for \%CL of OFT comparison of the Standard drug with Clitoral Bush (CB), followed by Mint (MP) and Bamboo (BP); \%CL comparison was found to be very significant $p<0.01$ 


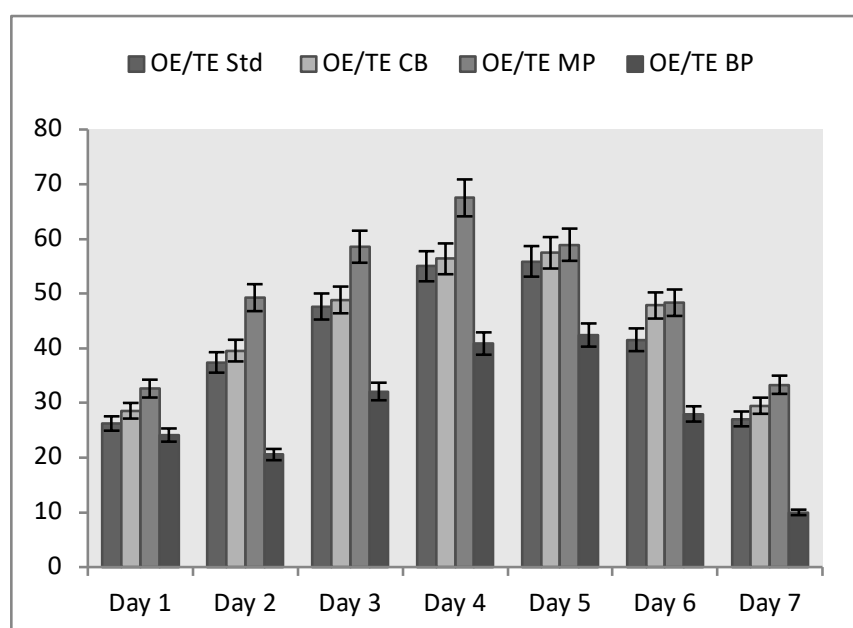

Fig. 3. Results for OE/TE of EPM test comparison of the Standard drug with Clitoral Bush (CB), followed by Mint (MP) and Bamboo (BP); OE/TE comparison was found to be significant $p<0.05$

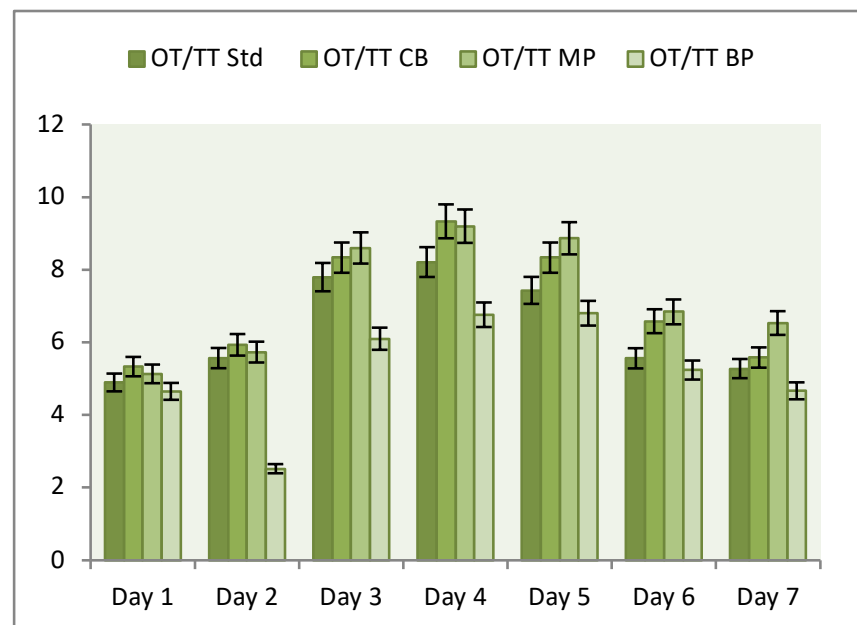

Fig. 4. Results for OT/TT of EPM test comparison of the Standard drug with Clitoral Bush (CB), followed by Mint (MP) and Bamboo (BP); OE/TE comparison was found to be very significant $p<0.01$

The current study was conducted as a mode of comparing three individual herbs whose anxiolytic efficacy has either not been tested ever before or if studied, was not done in recent years. Bamboo has not been tested before for its anxiolytic effect and to the best of our knowledge this is the first reporting of such study. Literature review found only one study of the anxiolytic effect of Clitoral bush that is more than 15 years old and the method used implemented the brutal use of electric shock and pentylenetetrazole injection [16]. Our study is radically different in methodology as we didn't use extraneous stress of any kind except for their natural reflex and instinct of staying in closed spaces while tested on Open Field Test (OFT) and Elevated Plus maze (EPM). Mentha piperita has been tested via measuring Plasma corticosterone after restraint stress and this study is also very different to our mode of conduct [17]. The three specimens showed positive stress reducing effect as compared to standard anxiolytic drug Diazepam for both the OFT and EPM as there were marked increase in their exploratory behaviour in open spaces and elevated points.

Open Field Test (OFT) is a long established psychological determinant test for stress assessment and coping. It is accepted globally as a simple tool for anxiolytic tests. The parameters vary depending on the experimental design and outcomes but typically parameters of Time spent in the center, Thigmotaxis (wall hugging or staying close to the outer perimeter of the test field, Rearing (standing on hindlegs, as an exploratory behaviour), urination, defecation, grooming, line crossing etc. are measured. In this study we have explored the parameters mentioned and also we have calculated additional parameters namely \%CT and $\% \mathrm{CL} . \% \mathrm{CT}$ is the percentage of center versus thigmotaxic duration and $\% \mathrm{CL}$ is the percentage of center duration versus total lines crossed. These two parameters are of the essence since they are analytical measures of the potency of the anxiolytic specimens tested. Staying in the center is the most important factor as rodents hate open space and they are stressed when put in open places. Their innate tendency is to stay away from open spaces. OF $\mathrm{T}$ has an open center which mimics danger for them while the walls are closed to enclosed spaces and they will naturally converge towards such. When anxiolytics work properly the stress levels are reduced and the rodents will show more exploratory behaviour such as higher $\% \mathrm{CT}$ and $\mathrm{CL}$ as well as more frequency of rearing and grooming. The current study in lieu to the previous published paper found no implicable increase in rearing, urination and defecation and so we are implying that these parameters might be affected.

For the Open Field test (OFT), the tables and figures are depicting that $\% \mathrm{CT}$ and $\% \mathrm{CL}$ has strong positive and measurable implicates. Fig. 1 is a depiction of \% CT (time ratio of center vs thigmotaxis) and Fig. 2 is for \%CL (ratio of center duration vs Line crossed). Fig. 1 shows that for all 7 days Clitoral Bush (CB) has the best anxiolytic effect followed by Mint (MP), Standard drug (STD) and lastly Bamboo (BP) respectively. \%CT states that $\mathrm{CB}$ is showing the highest positive anxiolytic effect. While Fig. 2 shows a slightly different picture. Here the first two days CB showed the highest effect but for the next 5 days Mint showed the highest impact, followed by standard and bamboo respectively. The $\mathrm{CB}$ and MP are contending strongly and are showing better results than standard drug Diazepam. Bamboo showed the least effect of them all. So in summary for OFT Clitoral Bush showed highest activity.

Elevated Plus Maize was an interesting test to carry out as that tests the reflex of the rodents to hide and stay away from open and heights at the same time. EPM tests, as the Fig. 3 and Fig. 4 along with Table III and IV show an inverse pattern in the graphical depiction as the results started low followed by gaining momentum and lastly the efficacy wearing down. Wherelse in OFT the results start as higher going down and then moving up trend. The OFT tests were done before the EPM. EPM test results agree with OFT as Clitoral Bush to have the highest potency and effectiveness as anxiolytic.

During the course of the trial we observed loss in weight in some of the group even though they were all put into same diet, living conditions, no extra stress by modifying their environment or comfort. Initially we concluded that the weight loss must be due to the stress of the trial, but then we observed some experimental group didn't lose while others did. Later we measured weight every week and the initial versus the last day of trial weights were analyzed and we found that Clitoral bush and Bamboo leaf tea helped lose weight while mint leaf tea didn't lose or gain weight. 
Diazepam on the other hand caused weight gain. Although weight loss by Clitoral bush was the highest among all. The pathophysiology of stress is that it causes our adrenal glands to release the hormone cortisol which holds on to fat as it prepares the body for fight or flight reflex. Therefore, stressed individuals often are obese or overweight [18]. Clitoral bush can not only calm the nerves it can also help lose weight by probably altering the mechanism of cortisol. When body doesn't have constant cortisol the metabolic rate will increase and hence weight loss can be initiated. The impact of the tea on the parameter of weight is depicted in Table $\mathrm{V}$ below.

TABLE V: DEPICTION OF THE PRE- AND POST-TRIAL WEIGHTS OF THE EXPERIMENTAL ANIMALS

\begin{tabular}{lcccc}
\hline \hline Groups & $\begin{array}{c}\text { Mean Pre- } \\
\text { Trial Weight } \\
\text { (gm) }\end{array}$ & $\begin{array}{c}\text { Mean Post- } \\
\text { Trial Weight } \\
\mathbf{( g m )}\end{array}$ & $\begin{array}{c}\% \\
\text { Change }\end{array}$ & Inference \\
\hline A/Control & 28.33333 & 32.16667 & +13.5 & $\begin{array}{c}\text { Wight } \\
\text { gained }\end{array}$ \\
\hline B/Std Low & 28.5 & 30.16667 & +5.80 & $\begin{array}{c}\text { Weight } \\
\text { gained }\end{array}$ \\
\hline C/Bamboo & 28.5 & 25.16667 & -11.69 & $\begin{array}{c}\text { Weight } \\
\text { Loss }\end{array}$ \\
\hline D/Mint & 29.2 & 29.2 & 00.00 & No Change \\
\hline $\begin{array}{l}\text { E/Clitoral } \\
\text { bush }\end{array}$ & 28.4 & 24.4 & -16.39 & $\begin{array}{c}\text { Weight } \\
\text { Loss }\end{array}$ \\
\hline \hline
\end{tabular}

Bamboo is typically growing in various patches around water bodies near human locality. It is a very useful since almost all parts are used in our lives. The young bamboo shoot is eaten in various Asian countries, the foliage is used for cattle raising, housing, the stalks in various stages are used in housing, making furniture etc. Bamboo has been integrated in the village life for thousands of years. The toxicity profile of Bamboo has been checked before choosing for this project and was found to be safe for consumption [19]. Bamboo has been found to be rich in polyphenols and flavonoids which are bioactive compounds that fight oxidative stress which leads to various diseases [20]. Hence it is shown in our study that Bamboo (Bambusa arundinacea) is effective to bring calmness, makes bamboo leaf tea a great healthy lifestyle companion for those who also need or want to lose weight. Our second natural stress buster was Mentha piperita or mint which we already know by its variety of uses from culinary, skincare, heathcare, pharmaceutical, skincare etc. [21]. Mint has been strongly recommended and found to have effect against nausea, indigestion, digestive complaints, cramping and anorexia $[22,23]$. For those who don't need or want to lose weight can use a warm cup of mint leaf tea to soothe the anxiety and restlessness. Our third and most verified stress busting and weight reducing specimen was Clitoral bush or Clitoria ternatea, whose aesthetic is a bonus too. The tea has a deep purple hue which makes the tea all more palatable. It has been shown to have the highest reduction effect and therefore can be used in place of modern chemical based medicine. It is one of the four ingredient of Shankha Pushpi, an ayurvedic neurological tonic [16]. It also has antiasthamatic effect, cardiovascular tonic and many other benefits along probably due to being rich in polyphenolic glycosides [16, 24]. Clitoria ternatea or as we commonly mentioned here as Clitoral bush has been shown to contain Brain-active compounds such as Taraxerol, Delphinidine based anthrocyannins called Ternatins, flavonoids, steroids and saponins, glycosides such as kaemferol and quercetin, biopesticide Finotin and unidentified trypsin inhibitors [25, 26]. Therefore, we can conclude that the presence of such a plethora of brain active compounds might synergistically work to alleviate brain function and bring about calmness.

\section{CONCLUSION}

Everyday life brings various emotions that are at times, hard to cope with and the modern life is now more complex than ever and certainly will not seize to be so. To be able to cope with all this now as much essential as healthy diet and exercise. Keeping calm can be helped naturally by implementing herbal means such as Clitoral bush, bamboo, mint or rose tea. Our experiment proved that bamboo, mint and Clitoral bush all have anxiety reducing properties along with weight loss property except for bamboo which shows no effect in weight gain or loss. On the other hand, employing chemical pills such as diazepam has myriads of side effect one of which is weight loss as seen in our experimental trial. The world needs to rely more on nature for holistically manage various psychosomatic disorders and diseases.

\section{ACKNOWLEDGEMENT}

The authors would like to extend their deep gratitude towards the Pharma Garden, Department of Pharmacy, Primeasia University for providing the organically grown sample for the study. Also

We are grateful for the support of Prof. Dr. Abdul Ghani, Head of the Department and Prof. Dr. Ehsanul Huq from the said department for their encouragement. The study was done via personal finance.

\section{REFERENCES}

[1] Glavin, G.B. Stress and brain noradrenaline: a review. Neuroscience \& Biobehavioral Reviews, 1985, 9(2), 233-243.

[2] Khansari, D.N.; Murgo, A.J.; Faith, R. E. Effects of stress on the immune system. Immunology Today, 1990, 11, 170-175.

[3] Steptoe, A.; Hamer, M.; Chida, Y. The effects of acute psychological stress on circulating inflammatory factors in humans: a review and meta-analysis. Brain, Behavior, and Immunity, 2007, 21(7), 901-912.

[4] Scott, S.B.; Graham-Engeland, J.E.; Engeland, C.G.; Smyth, J.M.; Almeida, D.M. The effects of stress on cognitive aging, physiology and emotion (ESCAPE) project. BMC Psychiatry, 2015, 15, 146.

[5] Innes, K.E.; Vincent, H.K. The influence of yoga-based programs on risk profiles in adults with type 2 diabetes mellitus: a systematic review. Evidence-Based Complementary and Alternative Medicine, 2007, 4(4), 469-486.

[6] Brown, R.P.; Gerbarg, P.L. Sudarshan Kriya yogic breathing in the treatment of stress, anxiety, and depression: part I-neurophysiologic model. Journal of Alternative \& Complementary Medicine, 2005, 11(1), 189-201.

[7] Tunna,T,S. Complementary and alternative medicinal approach to stress management. Frontiers Drug Chemistry Clinical Research, 2018, DOI: 10.15761/FDCCR.1000113

[8] Zhang, Y.; Yao, X.; Bao, B.; Zhang, Y. Anti-fatigue activity of a triterpenoid-rich extract from Chinese bamboo shavings (Caulis bamfusae in taeniam). Phytotherapy Research: An International Journal Devoted to Pharmacological and Toxicological Evaluation of Natural Product Derivatives, 2006, 20 (10), 872-876.

[9] Rathod, J.D.; Pathak, N.L.; Patel, R.G.; Jivani, N.P.; Bhatt Nayna, M. Phytopharmacological properties of Bambusa arundinacea as a potential medicinal tree: An Overview. Journal of Applied Pharmaceutical Science, 2011, 1(10), 27-31. 
[10] Sun, J.; Yue, Y.; Tang, F.; Guo, X. Simultaneous HPTLC analysis of flavonoids in the leaves of three different species of bamboo. JPCJournal of Planar Chromatography-Modern TLC, 2010, 23 (1), 40-45.

[11] Iscan, G.; KIrimer, N.; Kürkcüoglu Mn.; Baser, H.C.; Demirci, F. Antimicrobial screening of Mentha piperita essential oils. Journal of Agricultural Food Chemistry, 2002, 50, 3943-3946.

[12] Keifer, D.; Ulbricht, C.; Abrams, T.R.; Basch, E.; Giese, N. Peppermint (Mentha piperita) an evidence-based systematic review by the natural standard research collaboration. Journal of Herbal Medicine, 2008, 7, 91-143.

[13] Akram, M.; Uzair, M.; Malik, N.S.; Mahmood, A.; Sarwer, N. Madni, A., Asif, H.M. Mentha arvensis Linn.: A review article. Journal of Medicinal Plants Research, 2011, 5(18), 4499-4503

[14] Tunna, T.S.; Parvin, M.; Akter, M.S.; Jilhaz, M.; Mim, F.A.; Jahan, S.; Zaidul, I.S.M. Rose Petal tea as an axiolytic for stress management: An In Vivo study based on Elevated plus Maze and Open Field Test. International Journal of Pharmacy and Biological Sciences, 2019, 9(2), 587-597

[15] Finkel, R.; Clark, M.A.; Cubeddu, L.X. (Eds.). Pharmacology. Lippincott Williams \& Wilkins. Anxiolytic and Hypnotic Drugs, 2009, 9, 89-98.

[16] Jain, N.N.; Ohal, C.C.; Shroff, S.K.; Bhutada, R.H.; Somani, R.S.; Kasture, V.S.; Kasture, S. B. Clitoria ternatea and the CNS. Pharmacology Biochemistry and Behavior, 2003, 75(3), 529536.

[17] Parveen, T.; Amin, N.; Saleem, D.; Razi, F.; Haider, S.; Haleem, D.J. Antistress effect of Mentha piperita in rats and the role of brain serotonin and dopamine. Asian Journal of Pharmaceutical \& Biological Research, 2012, 2(1), 73-78

[18] Hewagalamulage, S.D.; Lee, T.K.; Clarke, I.J.; Henry, B.A. Stress, cortisol, and obesity: a role for cortisol responsiveness in identifying individuals prone to obesity. Domestic Animal Endocrinology, 2016, $56, \mathrm{~S} 112-\mathrm{S} 120$

[19] Akinmoladun, O.F.; Sabi, R.S.; Adedayo, O.T. Toxicological evaluation of graded levels of freshly harvested bamboo (Bambusa arundinacea) and tridax (Tridax procumbens) leaves on blood chemistry of rabbits. Nigerian Journal of Animal Production, 2018, $45(1), 183-197$

[20] Thamizharasan.S.; Umamaheswari.S.; Rajeswari, Hari, Ulagaratchagan.V. Quantitative Phytochemical Analysis of Bambusa arundinacea Seeds. The International Journal of Pharmacognosy and Phytochemical Research, 2015, 7(5), 980-983.

[21] Trevisan, S.C.C.; Menezes, A.P.P.; Barbalho, S. M.; Guiguer, É.L. Properties of Mentha piperita: a brief review. World Journal of Pharmacy and Medical Research, 2017, 3(1), 309-13.

[22] Keifer D,; Ulbricht C,; Abrams T.R,; Basch, E.; Giese, N. Peppermint (Mentha piperita) an evidence-based systematic review by the natural standard research collaboration. Journal of Herbal Medicine, 2008, 7, 91-143.

[23] Saeidnia S,; Gohari AR,; Yassa N,; Shafiee A. Composition of the volatile oil of achillea conferta dc. From Iran. DARU, 2005, 13, 3436.

[24] Kazuma, K.; Noda, N.; Suzuki, M. Malonylated flavonol glycosides from the petals of Clitoria ternatea. Phytochemistry, 2003, 62(2), 229237.

[25] Kumar, V.; Mukherjee, K.; Kumar, S.; Mal, M.; Mukherjee, P.K Validation of HPTLC method for the analysis of taraxerol in Clitoria ternatea. Phytochemical Analysis: An International Journal of Plant Chemical and Biochemical Techniques, 2008, 19(3), 244-250.

[26] Taur, D.J.; Patil, R.Y. Evaluation of antiasthmatic activity of Clitoria ternatea L. roots. Journal of ethnopharmacology, 2011, 136(2), 374376. 